\title{
The association of parent-child communication with Internet addiction in left-behind children in China
}

\author{
Jingjing Cai
}

Zhejiang University School of Medicine

\section{Yun Wang}

Washington University in Saint Louis School of Medicine

\section{Feng Wang}

Zhejiang University School of Medicine

Jingjing Lu

Zhejiang University School of Medicine

Xudong ZHOU ( $\nabla$ zhouxudong@zju.edu.cn )

Zhejiang University School of Medicine

Lu Li

Zhejiang University School of Medicine

\section{Research}

Keywords: left-behind children, Internet addiction, parent-child communication, paternal, maternal

Posted Date: July 27th, 2020

DOl: https://doi.org/10.21203/rs.3.rs-44979/v1

License: (c) (i) This work is licensed under a Creative Commons Attribution 4.0 International License.

Read Full License 


\section{Abstract \\ Background}

Long-term absence of parents has been proven to lead to negative health outcomes on left-behind children (LBC). We saw numerous studies that explored the association of parental absence with mental health and risky behaviors among LBC. Recently, Internet addiction has emerged as a growing concern, however, it was seldom studied among LBC community. This study aimed to compare the prevalence of Internet addiction between LBC and non-left-behind children (non-LBC), and explore the role of paternal and maternal parent-child communication on LBC.

\section{Methods}

We conducted a questionnaire survey in rural areas in Anhui, China, including the Parent-Adolescent Communication Scale and Young's Internet addiction Test. LBC who reported both migrating parents and children who lived with both non-migrating parents were included in this study.

\section{Results}

The complete data were available from 699 LBC and 740 non-LBC. After adjustment of socialdemographic characteristics, the result indicated LBC had a higher likelihood to report internet-addiction when compared to non-LBC $(O R=2.03,95 \% \mathrm{Cl}=1.43-2.88, \mathrm{p}<0.001)$. Among LBC, parent-child communication (both mother-child and father-child) was protective factors for children's Internet addiction. Also, the role of mother-child communication played well in preventing boys from Internet addiction.

\section{Conclusions}

Our findings suggested the lack of parental supervision may lead to Internet addiction. It is highly recommended for migrant parents to improve the quality of communication with their children. Also, gender-matching effects should be considered in the relationship between children's behavior and parental factors.

\section{Background}

The past few decades have witnessed rapid urbanization in China, with a sizable number of rural job hunters migrating from economically deprived areas to developed cities. Due to Chinese household registration systems[1], some social welfare services (e.g. free education at local public schools and coverage of medical insurance at local hospitals) are only provided to people with local "Hu Kou" (household registration at the municipal level)[2]. Thus, the majority of migrant parents will leave their 
children behind in the place of original residence registration, and therefore their children are referred in the literature as left-behind children (LBC) [3]. As estimated, in 2018, the number of LBC has reached 69 million[4]. Previous studies found that parental absence would put children at risk for mental health disorders and problem behaviors[5, 6]. A meta-analysis[7]demonstrated that LBC were more likely to develop depression, anxiety, suicidal ideation, conduct disorders and substance use. It has been proven that parental migration may result in unhealthy habits of children, of which Internet addiction was one of the those problem behaviors LBC reported[8].

The term Internet addiction is defined as an obsessive state and uncontrolled use of internet[9]. According to the data from China Internet Network Information Center (CINIC), as of June 2019, there were 854 million Chinese netizens, and the children under 19 accounted for 20.9\%[10]. Accompanying the increased internet and computer use, Internet addiction has increasingly recognized as a serious, worldwide public health concern in recent decades. Recent evidence suggested that Internet addiction could contribute to psychiatric symptoms and behavioral problems, such as substance use disorder, attention-deficit hyperactivity disorder, social anxiety disorder, and suicidal attempts[11, 12]. Moreover, the majority of LBC live with old-age grandparents[13]. Compared to parents, most of the grandparents have lower health literacy and may lack proper parenting knowledge and skills to supervise and monitor the grandchildren[8]. The migrant parents, presumably out of the guilt for their absence, tend to compensate their children financially, such as more pocket money. Lack of supervision and affordability of the devices and networks (for example, the internet café[14]) may facilitate the development of IA behavior in LBC.

To date, there has been some disagreement on the variation in Internet addiction behaviour between LBC and non-left-behind children (non-LBC). One school-based survey in three Chinese counties, enrolling students from grade 7 to grade 9 , revealed LBC $(n=593)$ were more likely to develop Internet addiction than non-LBC $(n=353)$ using an self-assessment questionnaire for adolescent problem behavior[15], while another cross-sectional study conducted in rural China, enrolling students from 8 to 17 years and using Young's 8-item Internet addiction Scale, reported that LBC had the lower prevalence of Internet addiction $(3.2 \%, n=1143)$ when compared to their rural counterparts $(3.7 \%, n=1287)$ [16]. According to an urban-based survey where Adolescent Pathological Internet Use Scale was utilized, there exhibited no group difference among Chongqing secondary school students $(n=796)$ in the risk of Internet addiction[17]. Diverse study sites, assessment tools, sample characteristics, and sample size may all contribute to the variance in these findings. Given these contradictory results, there was a need to investigate whether LBC more prone to Internet addiction than non-LBC or not.

Recent studies $[13,18-20]$ emphasized the role of parent-child communication in mitigating negative effects on LBC. Parent-child communication[21] refers to a dynamic procedure, where family members can exchange their information and emotion. Good-quality parent-child communication enhances family cohesion and helps family members overcome troubles[22]. Despite the well-established association between parent-child communication and mental health in $\operatorname{LBC}[18,20]$, such as life satisfaction, Ioneliness, happiness, and depressive symptoms, most studies in the field of parent-child communication have only focused on the quantity and frequency of the contacts between parents and children or topics 
they touched on rather than the quality of the communication $[13,18,19]$. It has been well noted that not only quantity but also quality of parent-child communication matters in alleviating adverse effects caused by parental migration[23]. Moreover, no research has looked at the potentially modifying role of parent-child communication in LBC's Internet addiction behavior. The gender difference was also found for children's Internet addiction and the quality of parent-child communication. A meta-analysis[24] of 119 independent samples from 34 countries/regions revealed that boys were more likely to have a higher level of Internet addiction than girls. Girls tend to be more active in conversation with parents than boys, and mothers seem likely to communicate with children rather than fathers. In consideration of the genderspecific effect, there was a need to examine paternal and maternal communication with sons and daughters, respectively.

The current study aimed to compared the prevalence of Internet addiction between LBC and non-LBC and investigated the association between gender-specific parent-child communication and Internet addiction among LBC.

\section{Methods}

\section{Participants and procedure}

Our study was a cross-sectional study using questionnaire surveys conducted in a school-based setting in Anhui Province in 2018. Anhui, a pioneering province in Southeastern China in the process of migration, had 16 million migrants for export in 2017[25]. Participants were recruited using a stratified multistage sampling design. Considering the economic level and the density of migrant worker, two counties (Wuwei and Nanling) were chosen as study sites in the first stage. Two towns were selected randomly from each county and in each town, one elementary school and one middle school were selected randomly according to the school roster of the Town Education Bureau. In these eight participating schools, all students from grade 5 to grade 8 were included in this study. Only children live with both non-migrant parents and left-behind children (living with neither migrant parent) were included. Children having reading and/or comprehension difficulties or reporting divorced or deceased parent were excluded.

\section{Measures}

\section{Internet addiction}

Students' Internet addiction behavior was assessed by using Young's Internet Addiction Test for Chinese (YIAT-C) [26, 27], a modified 20-item scale of Young's Diagnostic Questionnaire. Students were asked to select one response option to a 5-point Likert scale from "not at all" to "always". The scores for all 20 items were summed (therefore from 20 to 100), and a total score of 50 or beyond meant a presence of the Internet addiction behavior $[12,28]$. The reliability and validity of YIAT-C have been established in Chinese children[12], and in the present study, the Cronbach's alpha was 0.921. 


\section{Parental migration status}

Paternal and maternal migration status and presence was examined by two questions respectively, "has your father/your mother migrated into other places for work and been absent for over 6 months?". The child was identified as LBC if his/her response to both questions were "Yes, currently absent", and those living with both parents were considered as non-LBC.

\section{Parent-child communication}

The quality of parent-child communication was measured by the Chinese version Parent-Adolescent Communication Scale (PACS)[22]. PACS has 20 items, including two subscales of Openness of ParentAdolescent Communication (10 items) and Problems in Parent-Adolescent Communication (10 items). Items were rated on a 4-point Likert scale from 1 "strongly disagree" to 4 "strongly agree" to generate a total score and two subscale scores. A higher score indicates better parent-child communication. In the current study, the Cronbach's alpha of paternal and maternal communication scales were 0.916 and 0.892 , respectively.

\section{Demographic characteristics}

The social-demographic characteristics included gender, age, grade, siblings, family economic status, pocket money and possession of a computer. Family economic status was measured by subjective feelings of children because of the difficulty for children to judge the objective economic conditions of their families. The response item varies from "much poorer" to "much better" corresponding to their perception.

\section{Statistical analysis}

We presented participants' socio-economic characteristics in counts and percentages. Mann-Whitney test (for continuous variables) and chi-square test (for categorical variables) were employed to examine demographic characteristics and Internet addiction among LBC and non-LBC. The multivariate logistic regressions after adjustment for covariates were performed to examine whether LBC carried a higher risk

of developing Internet addiction. The covariates included grade, gender, possession of a computer, pocket money, any siblings and number of friends. Besides, interaction analyses of each covariate and parental migration status (LBC vs non-LBC) were tested to detect if the risk factors (e.g., gender) for Internet addiction differ statistically (with $p<0.05$ ) between LBC and non-LBC. Finally, we conducted logistic regressions to explore the association between parent-child communication and Internet addiction among LBC, and to determine whether the effects of parent-child communication had a gender-specific pattern through the interaction term.

\section{Ethics}

The Ethical Committee of Zhejiang University approved the study protocol. And local permission to conduct this survey was obtained from local government, school principals or administrators. All eligible students were provided with a detailed description of the study design and an informed consent form. 
Anonymous questionnaires were distributed to students who provided informed consent. Voluntary participation, withdrawn at any time, and the absence of a teacher ensured the anonymity of this investigation.

\section{Results}

A total of 1439 students agreed to participate in this study, of which 699 were LBC. Table 1 presents the social-demographic characteristics and Internet addiction. More than half of students were grade7 and grade8 (middle school) and boys. Approximately, two-thirds of respondents reported their family economic status as "average". The samples of LBC and non-LBC were comparable in terms of grade $(p=0.188)$, gender $(p=0.622)$, and family economic status $(p=0.622)$, but LBC group reported significantly less ownership of computers than non-LBC group $(p<0.05)$. A higher proportion of $(20.0 \%)$ LBC reported Internet addiction than non-LBC $(12.2 \%, \mathrm{p}<0.001)$.

Table 2 shows that parental migration is highly associated with Internet addiction, as well as other risk factors. After adjustments for socio-demographic characteristics, LBC were more than twice as likely to develop Internet addiction than non-LBC $(\mathrm{OR}=2.03,95 \% \mathrm{Cl}=1.43-2.88, \mathrm{p}<0.001)$. We did not observe any significant interaction terms between parental migration and other risk factors, implying that these risk factors for Internet addiction were equally important for LBC and non-LBC. Table 3 reveals that mother$(\mathrm{OR}=0.95,95 \% \mathrm{Cl}=0.92-0.98, \mathrm{p}<0.001)$ and father-child communication $(\mathrm{OR}=0.96,95 \% \mathrm{Cl}=0.94-0.99$, $p<0.01$ ) were both protective against Internet addiction among LBC. Compared with female LBC, motherchild communication showed significantly more effect on preventing male LBC from Internet addiction $(\mathrm{OR}=0.92,95 \% \mathrm{Cl}=0.86-0.98, \mathrm{p}<0.01)$. What is interesting in this data is that there exists no gender difference in father-child communication.

\section{Discussion}

The uncontrolled use of internet has led to disorders in psychological adjustments and health behaviors. Given the importance of parental company and supervision on preventing Internet addiction, this study aimed to explore the prevalence of Internet addiction and its risk factors across LBC and non-LBC. Based on our results, we have two main findings:1) LBC were more vulnerable to Internet addiction; 2) Parentchild communication was protective against Internet addiction among LBC, and the effect differed remarkably by gender of the parent and the child. Compared with father-child communication, the protective role of mother-child communication was specific to the child's gender, where mother-son communication was more effective than mother-daughter communication.

Parental absence has been well acknowledged as risk factors for child development $[5,29]$. In the present study, LBC were more likely to report Internet addiction. There are two possible psychological components to this issue: On the one hand, the internet provides children with an escape from negative events[5, 30]. Some authors have speculated that[31, 32], there existed unfulfilled emotional need among LBC, and internet has sometimes acted as a substitute for parents when children seek close contact and attention 
from the environment. Besides, the internet provided LBC with an approach to release their negative feelings. According to Young's theory[27], the internet could serve as a typical mode of compensation for negative events in LBC's lives, which referred to those caused by the absence of parental care and supervision. On the other hand, lack of parental supervision created an environment where children had easy access to internet, therefore leading to an high likelihood of Internet addiction. The social control theory suggested parental supervision has a protective effect against adolescent problem behaviors[33], and the inadequate parental supervision was proven in literature as a risk factor for Internet addiction[18].

Our study also served as the first-hand evidence for the protective role of parent-child communication against LBC's Internet addiction. A possible explanation for this might be that parent-child communication could affect Internet addiction through harmonious parent-child relationship. Good parent-child communication represented good parent-child relationship[34], while good parent-child relationship could effectively avoid Internet addiction among adolescents[35]. The other possible explanation might be the characteristics of good parent-child communication. Barnes and Olson[22] found that good communication with parents meant a free atmosphere of expression. In the context of mutual understanding, children will learn their emotional and social needs will be taken care of, which consequently reduces teens' motivation to go online. Therefore, our study might suggest that migrant parents should maintain sustainable communication with their children by ensuring both the quantity and quality of communication. Parents may learn to improved communication skills and extend the conversation topics to create a supportive communication atmosphere and enhance the quality of parentchild communication.

Interestingly, our study identified gender-specific influence of mother-child communication on Internet addiction: mother-child communication appeared to have a stronger effect on boys than girls.

Traditionally, mothers take on more responsibilities as caregivers[36] and tend to be more active in family communication. Daughters and sons respond differently to the dominant and proactive role the mothers play. Liu et al.[37] pointed out girls might be keener to build social relationships than boys. Levin et al.[38] found girls were prone to look for other positive relationships to deal with poor communication with parents. It could be speculated that there are fewer ways for boys to build social bonds with parents. When it comes to emotional expression and problem-solving, communicating with mothers might be more important for boys. Without this approach, boys are presumably more likely to turn to the internet, whereas girls may have more choices. The role of mothers in communication process[39] may be more critical for boys. However, the gender-specific effect was unobserved in father-child communication. A prior research[36] demonstrated that good communication with father was associated with fewer suicidal behaviors in the female group than in the male group. This gender-specific pattern was not a one-size-fitsall case for all kinds of problem behaviors. Luk et al.[34] pointed out mother-child communication could prevent sons from smoking, which was not seen in girls. Kelly et al.[40] reported less frequent alcohol use was found only in female adolescents when an emotional relationship with mother was close. Thus, it can be assumed that the protective association between family factors and adolescent problem behaviors might differ substantially across the gender (parents and children) and the type of behaviors. 
Considering diverse personality traits and behavioral preferences of male and female, it is recommended for further research to take gender-specific influence into account.

A number of important limitations need to be considered. First, the cross-sectional design limited our ability to draw a causal interpretation from our findings, especially the gender-specific influence. A longitudinal design is recommended for future studies to explore these issues. Second, we lacked the information on major caregivers and children's living condition. Although we considered these information in the design process, it's difficult to connect their parents in our pre-investigation. Thirdly, this survey relied on self-reports which could introduce bias (e. g., social desirability bias, recall biases). Finally, this study was only conducted in two counties in the southeast of China, which required more caution in extrapolating these findings to the whole country.

\section{Conclusions}

Our study highlighted the high likelihood of Internet addiction in LBC and expanded on prior knowledge by explicating how gender-specific parent-child communication were associated with Internet addiction among LBC. The current study suggested that migrant parents should pay attention to internet usage of their children, and keep good communication with their children.

\section{Abbreviations}

LBC

left-behind children

Non-LBC

non-left-behind children

\section{Declarations}

\section{Ethics approval and consent to participate}

The study was approved by the Ethical Committee of Zhejiang University (Ref no.ZGL201804-2).

\section{Consent for publication}

Not applicable.

\section{Availability of data and materials}

The data-sets analyzed during this study are available from the corresponding author on reasonable request.

\section{Competing interests}


The authors declare that they have no competing interests.

\section{Funding}

Zhejiang University Zijin Talent Project.

\section{Authors' contributions}

Jingjing Cai, Feng Wang, Jingjing Lu, Lu Li and Xudong Zhou conceived and designed the study. Jingjing Cai, Feng Wang, and Jingjing Lu collected the data. Jingjing Cai did the statistical analysis. Jingjing Cai and Yun Wang drafted the manuscript. All authors have approved the final version of the manuscript for publication.

\section{Acknowledgments}

The authors thank Zijin Talent Project, all participants in this study, as well as all the interviewers for data collection.

\section{References}

1. Chan KW, Zhang L. The hukou system and rural-urban migration in China: Processes and changes. The China Quarterly 1999(160):818-855.

2. Lu S, Lin Y, Vikse JH, et al. Well-being of migrant and left-behind children in China: Education, health, parenting, and personal values. INT J SOC WELF 2016;25(1):58-68.

3. Li Q, Liu G, Zang W. The health of left-behind children in rural China. CHINA ECON REV 2015 2015-0101;36:367-376.

4. Ministry Of Civil Affairs Of The People'S Republic Of China. Chart: Data of left-behind children in rural areas in 2018., 2018.

5. Tang W, Wang G, Hu T, et al. Mental health and psychosocial problems among Chinese left-behind children: A cross-sectional comparative study. J AFFECT DISORDERS 2018 2018-01-01;241:133-141.

6. Wang F, Lu J, Lin L, et al. Mental health and risk behaviors of children in rural China with different patterns of parental migration: a cross-sectional study. CHILD ADOL PSYCH MEN 2019 2019-0120;13(1):39.

7. Fellmeth G, Rose-Clarke K, Zhao C, et al. Health impacts of parental migration on left-behind children and adolescents: a systematic review and meta-analysis. The Lancet 2018 2018-1215;392(10164):2567-2582.

8. Gao Y, Li LP, Kim JH, et al. The impact of parental migration on health status and health behaviours among left behind adolescent school children in China. BMC PUBLIC HEALTH 2010 2010-0101;10(1):56.

9. Beard KW, Wolf EM. Modification in the proposed diagnostic criteria for internet addiction. CyberPsychology \& Behavior 2001 2001-06-01;4(3):377-383. 
10. CINIC. The 44th Statistical Report on Internet Development in China., 2019.

11. Jang KS, Hwang SY, Choi JY. Internet addiction and psychiatric symptoms among Korean adolescents. The Journal of School Health 2008;78:165-171.

12. Wang W, Zhou DD, Ai M, et al. Internet addiction and poor quality of life are significantly associated with suicidal ideation of senior high school students in Chongqing, China. PEERJ 2019 2019-07$17 ; 7(7): \mathrm{e} 7357$.

13. Xu Y, Xu D, Simpkins S, et al. Does it matter which parent is absent? Labor migration, parenting, and adolescent development in China. J CHILD FAM STUD 2019 2019-01-01;28(6):1635-1649.

14. Liu F. It is not merely about life on the screen: urban Chinese youth and the Internet café. J YOUTH STUD 2009 2009-01-01;12(2):167-184.

15. Fan X, Fang X. A Comparison of problem behaviors between left-behind children and children in gerenal (Chinese Article). Chinese Journal of Clinical Psychology 2010(2):232-234.

16. Guo J, Chen L, Wang X, et al. The relationship between internet addiction and depression among migrant children and left-behind children in China. Cyberpsychology, Behavior, and Social Networking 2012 2012-01-01;15(11):585-590.

17. Ge Y, Se J, Zhang J. Research on relationship among internet-addiction, personality traits and mental health of urban left-behind children. Global Journal of Health Science 2014 2014-12-17;7(4):60-69.

18. Su S, Li X, Lin D, et al. Psychological adjustment among left-behind children in rural China: the role of parental migration and parent-child communication. Child: Care, Health and Development 2013 2013-03-01;39(2):162-170.

19. Zhang X, Li M, Guo L, et al. Mental health and its influencing factors among left-behind children in South China: a cross-sectional study. BMC PUBLIC HEALTH 2019 2019-01-01;19(1):1711-1725.

20. Wang L, Feng Z, Yang G, et al. The epidemiological characteristics of depressive symptoms in the left-behind children and adolescents of Chongqing in China. J Affect Disord 2015 2015-0515;177:36-41.

21. Chen Y, Li L, Hu Y, et al. The Relationship between Parent-Child Communication and Internet Addiction of College Students in Hebei Province (Chinese article). Chinese Journal of School Health 2016(2).

22. Barnes HL, Olson DH. Parent-adolescent communication and the circumplex model. CHILD DEV 1985;56(2):438.

23. Zhao F, Yu G. Parental migration and rural left-behind children's mental health in China: A metaanalysis based on mental health test. J CHILD FAM STUD 2016;25(12):3462-3472.

24. Su W, Han X, Jin C, et al. Are males more likely to be addicted to the internet than females? A metaanalysis involving 34 global jurisdictions. COMPUT HUM BEHAV 2019 2019-01-01;99:86-100.

25. Statistics Bureau Of Anhui Province. Anhui data., 2017.

26. Ni X, Yan H, Chen S, et al. Factors Influencing internet addiction in a sample of freshmen university students in China. CyberPsychology \& Behavior 2009 2009-01-01;12(3):327-330. 
27. YOUNG KS. Internet addiction: The emergence of a new clinical disorder. CyberPsychology \& Behavior 1998;1(3):237-244.

28. Chung S, Lee J, Lee HK. Personal factors, internet characteristics, and environmental factors contributing to adolescent internet addiction: A public health perspective. International Journal of Environment Research and Public Health 2019;16(23).

29. Wang $F$, Lin $L, X u M$, et al. Mental health among left-behind children in rural China in relation to parent-child communication. INT J ENV RES PUB HE 2019 2019-05-26;16(10):1855.

30. Xin $\mathrm{M}$, Xing J, Pengfei $\mathrm{W}$, et al. Online activities, prevalence of Internet addiction and risk factors related to family and school among adolescents in China. Addictive Behaviors Reports 20182018 01-01;7:14-18.

31. Boniel-Nissim M, Sasson H. Bullying victimization and poor relationships with parents as risk factors of problematic internet use in adolescence. COMPUT HUM BEHAV 2018 2018-01-01;88:176-183.

32. Knight J, Song L, Huaibin J. Chinese rural migrants in urban enterprises: Three perspectives. J DEV STUD 1999 1999-01-01;35(3):73-104.

33. Ennett ST, Foshee VA, Bauman KE, et al. The social ecology of adolescent alcohol misuse. CHILD DEV 2008 2008-01-01;79(6):1777-1791.

34. Luk JW, Farhat T, lannotti RJ, et al. Parent-child communication and substance use among adolescents: Do father and mother communication play a different role for sons and daughters? ADDICT BEHAV 2010 2010-05-01;35(5):426-431.

35. Wang W, Li D, Li X, et al. Parent-adolescent relationship and adolescent internet addiction: A moderated mediation model. ADDICT BEHAV 2018 2018-01-01;84:171-177.

36. Lai Kwok SYC, Shek DTL. Hopelessness, parent-adolescent communication, and suicidal ideation among chinese adolescents in Hong Kong. SUICIDE LIFE-THREAT 2010 2010-06-01;40(3):224-233.

37. Liu W, Mei J, Tian L, et al. Age and gender differences in the relation between school-related social support and subjective well-being in school among students. SOC INDIC RES 2016 2016-0101;125(3):1065-1083.

38. Levin KA, Dallago L, Currie $C$. The association between adolescent life satisfaction, family structure, family affluence and gender differences in parent-child communication. SOC INDIC RES 2012 201201-01;106(2):287-305.

39. Wilson EK, Koo HP. Mothers, fathers, sons, and daughters: gender differences in factors associated with parent-child communication about sexual topics. REPROD HEALTH 2010 2010-12-14;7(1):31.

40. Kelly AB, O'Flaherty M, Toumbourou JW, et al. Gender differences in the impact of families on alcohol use: a lagged longitudinal study of early adolescents. ADDICTION 2011 2011-08-01;106(8):14271436.

\section{Tables}


Table 1 Social demographic characteristics of rural children by parent migration status, $\mathrm{n}$ (\%)

\begin{tabular}{|c|c|c|c|c|}
\hline & LBC & Non-LBC & $\mathrm{Z}^{*}$ or $\mathrm{c}^{2}$ & $p$ value \\
\hline Total & 699 & 740 & & \\
\hline Age, mean (SD) & $12.4(1.2)$ & $12.5(1.2)$ & 0.596 & 0.551 \\
\hline Grade & & & 1.73 & 0.188 \\
\hline Grade5 and Grade6 & $323(46.2)$ & $316(42.8)$ & & \\
\hline Grade7 and Grade8 & $376(53.8)$ & $423(57.2)$ & & \\
\hline Gender & & & 0.244 & 0.622 \\
\hline Male & $380(55.0)$ & $393(53.7)$ & & \\
\hline Female & $311(45.0)$ & $339(46.3)$ & & \\
\hline Having any siblings & & & 2.292 & 0.13 \\
\hline Yes & $450(64.6)$ & $505(68.3)$ & & \\
\hline No & $247(35.4)$ & $234(31.7)$ & & \\
\hline Friends number, mean (SD) & $5.0(3.3)$ & $5.1(3.2)$ & 0.557 & 0.577 \\
\hline Economic status & & & 0.95 & 0.622 \\
\hline Much better/better & $193(27.8)$ & $205(28.0)$ & & \\
\hline Average & $455(65.7)$ & $470(64.2)$ & & \\
\hline Much poorer/poorer & $45(6.5)$ & $57(7.8)$ & & \\
\hline Computer & & & 4.656 & 0.031 \\
\hline No & $350(50.1)$ & $329(44.5)$ & & \\
\hline Yes & $348(49.9)$ & $411(55.5)$ & & \\
\hline Pocket money & & & 4.451 & 0.108 \\
\hline 0 & $136(19.5)$ & $175(23.8)$ & & \\
\hline $1-6$ & $308(44.2)$ & $295(40.2)$ & & \\
\hline$>6$ & $253(36.3)$ & $264(36.0)$ & & \\
\hline Internet addiction, $\mathrm{n}(\%)$ & & & 12.263 & $<0.001$ \\
\hline No (IA group<=49) & $424(80.0)$ & $495(87.8)$ & & \\
\hline Yes (IA group $>=50$ ) & $106(20.0)$ & $69(12.2)$ & & \\
\hline
\end{tabular}

Note. Z: Mann-Whitney Test; SD: standard deviation; IA: Internet addiction; LBC: left-behind children

Table 2 Parent migration and its risk factors in relation to Internet addiction 


\begin{tabular}{lc}
\hline & OR (95\%CI) \\
\hline Parental migration & 1 \\
N-LBC & $2.03(1.43,2.88)^{* * *}$ \\
LBC & 1 \\
Grade & $2.53(1.71,3.73)^{* * *}$ \\
Grade5 and Grade6 & 0.470 \\
Grade7 and Grade8 & 1 \\
$p$ for interaction term & $1.44(1.01,2.05)^{*}$ \\
Computer & 0.213 \\
No & 1 \\
Yes & $1.67(0.97,2.87)$ \\
$p$ for interaction term & $2.14(1.25,3.65)^{* *}$ \\
Pocket money & 0.437 \\
0 & 1 \\
$1-6$ & $1.47(1.03,2.10)^{*}$ \\
$>6$ & 0.806 \\
$p$ for interaction term & \\
Gender & 1 \\
Female & \\
Male & $1.42(0.97,2.08)$ \\
$p$ for interaction term & 0.708 \\
Do you have any siblings? & $0.97(0.94,1.01)$ \\
No & 0.615 \\
Yes & \\
$p$ for interaction term & \\
Friends number & \\
$p$ for interaction term & \\
\hline
\end{tabular}

Note. CI: Confidence interval; OR: Odds ratio; LBC: left-behind children; ${ }^{*}: \mathrm{p}<0.05 ;{ }^{* *}: \mathrm{p}<0.01 ;{ }^{* * *}: \mathrm{p}<0.001$.

Table 3 The association between parent-child communication and Internet addiction among LBC 


\begin{tabular}{|c|c|c|}
\hline & $\begin{array}{c}\text { Model } 1 \text { Outcome: Internet } \\
\text { addiction } \\
\text { OR }(95 \% \mathrm{CI})\end{array}$ & $\begin{array}{c}\text { Model } 2 \text { Outcome: Internet } \\
\text { addiction } \\
\text { OR }(95 \% \mathrm{CI})\end{array}$ \\
\hline $\mathrm{MCC}^{1}$ & $0.95(0.92,0.98)^{* * *}$ & $0.99(0.95,1.03)$ \\
\hline $\mathrm{FCC}^{2}$ & $0.96(0.94,0.99)^{* *}$ & $0.94(0.90,0.98)^{* *}$ \\
\hline Grade & & \\
\hline Grade5 and & 1 & 1 \\
\hline Grade6 & & \\
\hline $\begin{array}{l}\text { Grade7 and } \\
\text { Grade8 }\end{array}$ & $2.23(1.30,3.82)^{* *}$ & $2.34(1.36,4.05)^{* *}$ \\
\hline Computer & & \\
\hline No & 1 & 1 \\
\hline Yes & $2.14(1.31,3.49)^{* *}$ & $2.11(1.28,3.46)^{* *}$ \\
\hline Gender & & \\
\hline Female & 1 & 1 \\
\hline Male & $1.31(0.81,2.13)$ & $11.75(0.49,281.79)$ \\
\hline MCC*Gender & & \\
\hline MCC*Female & & 1 \\
\hline MCC*Male & & $0.92(0.86,0.98)^{* *}$ \\
\hline FCC*Gender & & \\
\hline FCC*Female & & 1 \\
\hline FCC*Male & & $1.04(0.99,1.10)$ \\
\hline
\end{tabular}

Note. CI: Confidence interval; OR: Odds ratio; ${ }^{*}: \mathrm{p}<0.05 ;{ }^{* *}: \mathrm{p}<0.01 ;{ }^{* * *}: \mathrm{p}<0.001 ;{ }^{1}$ : Mother-child communication; ${ }^{2}$ : Father-child communication. 